\title{
Sound Practice-improving occupational health and safety for professional orchestral musicians in Australia
}

\author{
Bronwen J. Ackermann ${ }^{1}{ }^{*}$, Dianna T. Kenny ${ }^{2}$, Ian O'Brien ${ }^{1}$ and Tim R. Driscoll ${ }^{3}$ \\ ' School of Medical Sciences, Sydney Medical School, University of Sydney, Sydney, NSW, Australia \\ ${ }^{2}$ Faculty of Arts and Social Sciences, University of Sydney, Sydney, NSW, Australia \\ ${ }^{3}$ School of Public Health, Sydney Medical School, University of Sydney, Sydney, NSW, Australia
}

\section{Edited by:}

Matthew A. Wyon, University of

Wolverhampton, UK

Reviewed by:

Derrick D. Brown, Radboud

University Nijmegen, Netherlands

Emma Redding, Trinity Laban

Conservatoire of Music and Dance, UK

\section{${ }^{*}$ Correspondence}

Bronwen J. Ackermann, University of Sydney, Cumberland Campus,

Room L110A, PO Box 170,

Lidcombe, Sydney, NSW 1825,

Australia

e-mail: bronwen.ackermann@

sydney.edu.au
The Sound Practice Project is a 5-year study involving baseline evaluation, development, and implementation of musician-specific work health and safety initiatives. A cross-sectional population physical and psychological survey and physical assessment were conducted at the same time, with an auditory health assessment conducted later. The results were used to guide the development of a series of targeted interventions, encompassing physical, psychological, and auditory health components. This paper provides an overview of the project but focuses on the health findings arising from the cross-sectional survey. Three hundred and seventy-seven musicians from the eight professional symphony orchestras in Australia took part in the cross-sectional study (about $70 \%$ of eligible musicians). Eighty-four percent (84\%) of musicians reported past performance-related musculoskeletal disorder (PRMD) episodes; $50 \%$ were suffering a current PRMD. Of the $63 \%$ who returned hearing surveys, $43 \%$ believed they had hearing loss, and $64 \%$ used earplugs at least intermittently. Noise exposure was found to be high in private practice, although awareness of risk and earplug use in this environment was lower than in orchestral settings. Improved strategic approaches, acoustic screens and recently developed active earplugs were found to provide effective new options for hearing protection. With respect to psychosocial screening, female musicians reported significantly more trait anxiety, music performance anxiety, social anxiety, and other forms of anxiety and depression than male musicians. The youngest musicians were significantly more anxious compared with the oldest musicians. Thirty-three percent (33\%) of musicians may meet criteria for a diagnosis of social phobia; $32 \%$ returned a positive depression screen and $22 \%$ for post-traumatic stress disorder (PTSD). PRMDs and trigger point discomfort levels were strongly associated with increasing severity of psychological issues such as depression and music performance anxiety.

Keywords: professional orchestral musicians, music performance anxiety, performance-related musculoskeletal disorders, workplace health and safety, noise-induced hearing loss

\section{INTRODUCTION}

Professional orchestral musicians are required to practice highly complex actions for many hours on a daily basis to develop the elite skills that enable them to perform classical masterpieces in prestigious venues under the scrutiny of large and mostly discerning audiences. To be able to achieve this kind of success in this competitive industry requires optimal physical and psychological functioning of the musician. Such a high-pressured workplace often requires musicians to push their physiological boundaries to the limit, thereby making them highly vulnerable to injury. Since the 1980s, literature consistently reports significant health concerns, including high rates of performance-related injuries, psychological health issues such as music performance anxiety, and reports of noise-induced hearing loss (NIHL). In 2009 a team of University of Sydney researchers were funded to undertake an occupational health project, the Sound Practice project, which comprehensively investigated the health of orchestral musicians across Australia. An initial baseline cross-sectional survey of the physical and psychological health of the population, and a physical assessment, were conducted at the beginning of the study, with an auditory health assessment conducted later. The results of these assessments were used to guide the development of a series of targeted interventions, encompassing physical, psychological, and auditory health components (Figure 1). This paper provides an overview of the background to the project and presents a summary of the main health findings of the cross-sectional component of the study which underpinned the interventions that were later piloted. These have been reported in more detail elsewhere (Ackermann et al., 2012; Driscoll and Ackermann, 2012; Kenny et al., 2012; O'Brien et al., 2012; Kenny and Ackermann, 2013).

\section{PHYSICAL ASPECTS AND INJURY}

Literature documenting the health risks and high rates of injury faced by musicians internationally has been steadily building over the last few decades, and yet the statistics of players suffering 


\section{SOUND PRACTICE PROJECT MILESTONES}

\begin{tabular}{|c|c|c|c|c|c|c|c|c|c|c|c|c|}
\hline \multirow{3}{*}{ PROJECT PHASE } & \multicolumn{2}{|c|}{2009} & \multicolumn{2}{|c|}{2010} & \multicolumn{2}{|c|}{2011} & \multicolumn{2}{|c|}{2012} & \multicolumn{2}{|c|}{2013} & \multicolumn{2}{|c|}{2014} \\
\hline & YEA & R ONE & YEA & TWO & YEA & THREE & YEA & FOUR & & R FIVE & CONSC & LIDATION \\
\hline & $\begin{array}{l}0-6 \\
\text { months }\end{array}$ & $\begin{array}{l}6-12 \\
\text { months }\end{array}$ & $\begin{array}{l}12-18 \\
\text { months }\end{array}$ & \begin{tabular}{|l|}
$18-24$ \\
months
\end{tabular} & $\begin{array}{l}24-30 \\
\text { months }\end{array}$ & $\begin{array}{l}30-36 \\
\text { months }\end{array}$ & $\begin{array}{l}36-42 \\
\text { months }\end{array}$ & $\begin{array}{l}42-48 \\
\text { months }\end{array}$ & $\begin{array}{l}48-54 \\
\text { months }\end{array}$ & $\begin{array}{l}54-60 \\
\text { months }\end{array}$ & $\begin{array}{l}60-66 \\
\text { months }\end{array}$ & $\begin{array}{l}66-72 \\
\text { months }\end{array}$ \\
\hline $\begin{array}{l}\text { Collate baseline data } \\
\text { (premiums, DALYs) }\end{array}$ & $x$ & & & & & & & & & $\mathrm{x}$ & & \\
\hline $\begin{array}{l}\text { Comprehensive health } \\
\text { assessment }\end{array}$ & $x$ & & & & & & & & & $x$ & & \\
\hline $\begin{array}{l}\text { Establish and run injury } \\
\text { surveillance system }\end{array}$ & & $x$ & $x$ & $\mathrm{x}$ & $\mathrm{x}$ & $x$ & $\mathrm{x}$ & $\mathrm{x}$ & $\mathrm{x}$ & $x$ & & \\
\hline $\begin{array}{l}\text { Feedback-based } \\
\text { intervention trials }\end{array}$ & & $x$ & $\mathrm{x}$ & $\mathrm{x}$ & $\mathrm{x}$ & $\mathrm{x}$ & & & & & & \\
\hline $\begin{array}{l}\text { Surveillance-based } \\
\text { targeted intervention } \\
\text { trials }\end{array}$ & & & & $x$ & $\mathrm{x}$ & $\mathrm{x}$ & $\mathrm{x}$ & $\mathrm{x}$ & $\mathrm{x}$ & $\mathrm{x}$ & & \\
\hline $\begin{array}{l}\text { Draft OH\&S procedural } \\
\text { document }\end{array}$ & & & & & & & & $\mathrm{x}$ & $\mathrm{x}$ & & & \\
\hline Trial OH\&S procedures & & & & & & & & & $\mathrm{x}$ & $\mathrm{x}$ & & \\
\hline $\begin{array}{l}\text { Review and finalise OH\&S } \\
\text { policy }\end{array}$ & & & & & & & & & & $\mathrm{x}$ & $\mathrm{x}$ & $\mathrm{x}$ \\
\hline
\end{tabular}

FIGURE 1 | Sound Practice Project-initial project timetable.

performance-related injuries has remained essentially unchanged (Fry, 1986; Fishbein et al., 1988; Leaver et al., 2011; Paarup et al., 2011; Ackermann et al., 2012). Most reports indicate that approximately $80 \%$ of players will experience an injury that affects their ability to play their instrument, and that these performancerelated injuries are even common amongst the school aged talented students (Ranelli et al., 2011).

While playing related overuse or misuse have been commonly cited as the generic cause of injuries occurring to this population (Fry, 1986; Meinke, 1998), it is becoming increasing clear that a multitude of risk factors are involved in injury causation (Manchester, 2007; Brandfonbrener, 2010). Lack of prospective injury surveillance data hampers attempts to infer injury causality from exposure to previously identified risk factors (Ackermann and Adams, 2004; Brandfonbrener, 2010).

In an orchestra review published in Australia in 2005, the author noted that orchestral occupational health and safety practices could be significantly improved world-wide, and recommended that funding be allocated to address this issue in the Australian orchestras (Strong, 2005). The Sound Practice project answered this call to perform a longitudinal occupational health study of the eight main professional orchestras in Australia over a 5-year period. The project comprehensively investigates the health and well-being of professional orchestral musicians and trials various health-focused programs and interventions.

\section{PSYCHOLOGICAL ASPECTS}

International surveys of professional orchestral musicians have always reported high rates of music performance anxiety (Fishbein et al., 1988; James, 1997, 1998) but the studies are old and did not use standardized assessment tools, making comparisons among studies impossible. Thus, to date, the mental health of professional musicians has not been well-understood; hence, their mental health needs are often poorly managed. Psychosocial health including health behaviors such as substance and alcohol use have not been systematically studied and this needed to occur in order that health prevention programs target the appropriate health behaviors for the appropriate subgroups if these be identified.

Despite relationships between pain and stress, and anxiety and depression having been extensively examined in different pain populations, few studies have assessed these relationships in populations of professional orchestral musicians. The results of our study demonstrated an interactive relationship between psychological factors, such as music performance anxiety and depression and playing-related musculoskeletal symptoms. It is 
also possible that performance-related musculoskeletal disorders have an impact on psychological wellbeing. Evidence of an interactive impact between hearing and psychological health, with self-reported hearing problems associated with a perceived poorer psychosocial environment, mental health symptoms and stress has been observed in this population (Hasson et al., 2009).

While more work is needed, particularly the conduct of longitudinal studies that track the young musician from entry into an orchestra over a number of years to assess causal mechanisms for physical and mental health concerns, the current research has highlighted complex relationships between psychological health and physical factors that would be profitable to explore further with a view to developing effective management and treatments for the impaired musician. It is possible that may have some kind of similar complex relationship.

\section{NOISE}

It is by now well-established that, while playing in the orchestra, orchestral musicians may be exposed to levels of sound that risk permanent damage to their hearing. There have been many sound level surveys of orchestras published in the literature, most in the last 40 years. These studies have used a variety of methods and interpretations, but many have reached the conclusion that the risk of NIHL in the orchestra is highly variable dependent upon instrument type, venue, repertoire, and duration of exposure, and that the greatest exposure is generally from a musicians' own instrument (Axelsson and Lindgren, 1981; Jansson and Karlsson, 1983; Lee et al., 2005; O’Brien et al., 2008; Schmidt et al., 2011).

Audiological investigations have produced conflicting results, with some finding limited evidence of hearing loss (Jansson and Karlsson, 1983; Obeling and Poulsen, 1999; Kähäri et al., 2001), although many more have found that professional orchestral musicians exhibit greater incidence of noise-related hearing pathologies (including permanent threshold shift, tinnitus, and hypercusis) than the general population (Emmerich et al., 2008; Jansen et al., 2009; Pawlaczyk-Łuszczyńska et al., 2010; Toppila et al., 2011). Evidence of increased incidence of hearing loss amongst the higher exposed musicians in this population continues to emerge (Wilson et al., 2013).

As Australia's orchestras all had some form of hearing conservation in place at the commencement of the Sound Practice study, the current strategies and approaches used by orchestral managements were investigated. In addition, the hearing conservation habits and attitudes of the musicians were examined. This information was used as the basis of recommendations to improve noise control measures.

\section{MATERIALS AND METHODS PARTICIPANTS}

Australia has eight full-time professional symphonic and pit orchestras located in each of the capital cities of Australia. Their musicians represent the country's most elite orchestral musician population. With few elite positions available for a relatively large number of aspiring musicians, intense competition exists to acquire a position in one of these professional orchestras. All orchestral musicians employed by these eight major state orchestras were invited to participate in the study. This included permanent and casual musicians.

\section{PHYSICAL}

A baseline questionnaire was developed that incorporated pain and injury questions refined from a variety of sources including previous musicians' health research surveys developed by one of the authors (BA); existing commonly used survey tools; and additional musician-specific questions recommended by leading international musicians' medicine experts. This was completed by participants at the beginning of the study.

A team of trained physical therapists conducted a baseline physical examination on each participating musician. This protocol was developed by one of the authors (BA) and was based on current best-evidence guides. A protocol was developed using a range of procedures to test strength, range of motion, neural sensitivity, and fine motor control (Ackermann and Driscoll, 2010). All testers attended a protocol-training day and were given a detailed booklet to optimize consistency. Inter-rater reliability tests were conducted. The testing took place at each orchestra location and took approximately $1 \mathrm{~h}$ per musician (in addition to the $1 \mathrm{~h}$ for the physical and psychological health surveys).

\section{PSYCHOLOGICAL}

\section{Assessment of psychological characteristics of professional orchestral musicians}

This cross-sectional population survey of the musicians $(n=$ 377 ) consisted of a detailed questionnaire, administration of standardized psychological tests and a physical examination. The aim was to assess the prevalence and reported causes of music performance anxiety within this population, and to provide some normative data on a range of psychological screening tests for professional musicians.

A range of validated psychosocial measures were included. These were: Kenny Music Performance Anxiety Inventory (Revised) (K-MPAI) (Kenny, 2009) $)^{1}$; Trait questionnaire of the StateTrait Anxiety Inventory (STAI-T) (Spielberger et al., 1983); Social Phobia Inventory (SPIN) (Connor et al., 2000); PRIMEMD Patient Health Questionnaire [PRIME-MD PHQ (Spitzer et al., 1999)]; Anxiety and Depression Detector [ADD (MeansChristensen et al., 2006)]; Core Self Evaluation Scale [CSE (Judge et al., 2003)]; and Alcohol Use Disorders Identification Kit [AUDIT (Babor et al., 2001)]. Detailed descriptions of these scales can be found in Kenny et al. (2012).

In the absence of suitable instruments, a number of checklists, questionnaires, and scales were developed specifically for this study. These included:

(i) Performance anxiety in different performance settings rating scale (Kenny, 2011).

(ii) Workplace satisfaction scale for musicians (Kenny, 2009).

(iii) Workplace environment scale for musicians (Kenny, 2009).

(iv) Causes of Music Performance Anxiety Checklist (Kenny, 2011).

\footnotetext{
${ }^{1}$ Questionnaires developed for Sound Practice project and included in baseline questionnaire. See also Kenny et al. (2012) for detailed descriptions.
} 
(v) Self-management of music performance anxiety rating scale (Kenny, 2011).

\section{In-depth psychological interviews}

A series of in-depth interviews were conducted with a sub-group of orchestral musicians who self-identified as suffering from extremely severe levels of MPA. All 20 interviews were audiotaped and transcribed in full. The aim of the analysis was to extract common themes in the transcripts that would provide a nuanced insight into the psychological lives of orchestral musicians in order to gain further insight into their psychodynamics and to potentially guide and tailor management and treatment for this group.

Trial therapy of Intensive Short-Term Dynamic Psychotherapy (ISTDP). Eight musicians meeting the criteria for severe music performance anxiety (MPA) self-selected to participate in a trial treatment of ISTDP (Davanloo, 1990, 2001). All sessions were video-recorded with permission of participants and analyzed with respect to the possible etiological role that an underlying attachment disorder had on their unremitting MPA. This trial constitutes the first application internationally of ISTDP with professional musicians who had suffered severe MPA (Type 3: unresolved attachment disorder (see Kenny, 2011); also classified as fragile character structure (Davanloo, 1990, 1995).

\section{HEARING}

A hearing health survey was conducted using a questionnaire developed for the study. This questionnaire assessed hearing conservation behaviors and the prevalence of self-perceived hearing loss. After pilot testing, it was distributed to 580 musicians across the eight participating professional orchestras. The hearing survey was administered a year after the initial physical and psychological health surveys, and took approximately $10 \mathrm{~min}$ for each musician to complete.

The noise exposure in practice rooms was assessed with 35 professional orchestral musicians (representing players of most orchestral instruments). These musicians were individually assessed using recording devices (Type 1 integrating sound levels meters) at each ear and in front of players as they performed a comparable pre-set practice routine in the same controlled environment.

\section{SURVEILLANCE}

Several attempts were made to implement injury surveillance monitoring over the course of the project. Three independent approaches were trialed-one paper-based and then two webbased asking essentially the same questions. The first two were conducted within the first two and half years of the study and the third is on-going. The questions related to both playing and nonplaying exposures faced by musicians, four psychological screening questions, perceived playing exertion levels [using the BORG scale (Borg, 1998)] as well as relevant outcomes (performancerelated musculoskeletal disorder-PRMDs_and time lost from work) within a defined time period.

\section{ETHICS}

Ethics approval was granted by the University of Sydney Human Ethics Committee (ref: HREC1254).

\section{RESULTS}

From the total $(n=580)$ potential participants, 377 professional orchestral musicians (184 males, 192 females) participated in the baseline surveys (65\% response rate), while a slightly higher number completed a physical assessment (70\% response rate-408 in total; 199 males and 206 females (and three with unrecorded gender). More people completed the physical assessment because some people did not return fully-completed questionnaires. The mean age was 42.1 years $(S D=10.2)$. The type of instruments played by the included musicians was a good reflection of the full orchestra complement in the eight included orchestras (Table 1).

Table 1 | Instrument distribution in subjects included in the questionnaire and physical parts of the Sound Practice study.

\begin{tabular}{|c|c|c|c|c|}
\hline \multirow[t]{2}{*}{ Instrument } & \multicolumn{2}{|c|}{ Questionnaire } & \multicolumn{2}{|c|}{ Physical } \\
\hline & No. & $\%$ & No. & $\%$ \\
\hline \multicolumn{5}{|c|}{ UPPER STRINGS } \\
\hline Violin & 115 & 30.5 & 127 & 31.4 \\
\hline Viola & 54 & 14.3 & 55 & 13.9 \\
\hline Total & 169 & 44.8 & 182 & 44.9 \\
\hline \multicolumn{5}{|c|}{ LOWER STRINGS } \\
\hline Cello & 46 & 12.2 & 48 & 11.9 \\
\hline Double bass & 22 & 5.8 & 26 & 6.4 \\
\hline Total & 68 & 18.0 & 74 & 18.3 \\
\hline \multicolumn{5}{|l|}{ WOODWIND } \\
\hline Flute & 21 & 5.6 & 22 & 5.4 \\
\hline Oboe & 18 & 4.8 & 18 & 4.4 \\
\hline Bassoon & 15 & 4.0 & 17 & 4.2 \\
\hline Clarinet & 13 & 3.4 & 14 & 3.5 \\
\hline Total & 67 & 17.8 & 71 & 17.5 \\
\hline \multicolumn{5}{|l|}{ BRASS } \\
\hline French horn & 28 & 7.4 & 28 & 6.9 \\
\hline Trombone & 16 & 4.2 & 17 & 4.2 \\
\hline Trumpet & 10 & 2.7 & 12 & 3.0 \\
\hline Tuba & 4 & 1.1 & 4 & 1.0 \\
\hline Total & 58 & 15.4 & 61 & 15.1 \\
\hline \multicolumn{5}{|c|}{ PERCUSSION AND TYMPANI } \\
\hline Percussion & 7 & 1.9 & 7 & 1.7 \\
\hline Tympani & 5 & 1.3 & 6 & 1.5 \\
\hline Total & 12 & 3.2 & 13 & 3.2 \\
\hline Other & 3 & 0.8 & 4 & 1.0 \\
\hline Total & 377 & 100.0 & 408 & 100.0 \\
\hline
\end{tabular}

Number and percent. 


\section{PHYSICAL \\ PRMD}

Eighty four percent of the 377 participants who completed a questionnaire reported a past history of PRMDs, and $49 \%$ of the total reported PRMDs that lasted longer than a week and that were present at the time of the survey. For half of these players, PRMDs had been present for longer than 3 months. Of the $84 \%$ of musicians reporting previous performance-related injuries, on average only $40 \%$ reported full recovery from these conditions. Some of the more commonly reported pain regions, such as the shoulders, were associated with some of the worst scores in relation to recovery, averaging only $18.9 \%$ (left) and $26.4 \%$ (right) of players who reported full recovery (Ackermann et al., 2012). It is not possible to ascertain from our study whether these poor recovery rates were a consequence of inadequate rehabilitation and/or were due to the severity of the injury itself.

Injuries were most commonly reported in the spine and shoulders, but the most prevalent sites varied in relation to instrumental groups. For example, pain in the right elbow and forearm was more common for woodwind players than all other instrumental groups and typically pain was more common on the left upper limb than the right (see Table 2), despite these players having the highest scores in dexterity using the Purdue Pegboard test (Ackermann and Driscoll, 2010). The pain results by instrument group have been published previously in detail (Ackermann et al., 2012). Stratifying the results further by individual instrument played shows injury patterns that appear to be clearly related to the static and dynamic physical demands associated with playing that instrument. For example, baseline physical self-report data revealed that trombonists were significantly more likely to report left shoulder PRMDs than cellists ( $50 \%$ vs. $20 \%, p=0.02$ ), while the reverse occurred with right shoulder PRMDs, with cellists being significantly more prone to these injuries than trombonists $(46 \%$ vs. $19 \%, p=0.04)$. No gender effects were noted, and physical examination using a range of standard clinical tests for the shoulder did not reveal any differences related to these two instruments in terms of strength or range of motion (Driscoll and Ackermann, 2012).

\section{Perceived exertion}

The perceived exertion was rated as higher for performance than for rehearsing or for private practice. This was true whether the musician played in a stage or pit orchestra.
Psychological. All psychological screening tests for anxiety and depression (i.e., trait anxiety, social phobia, and music performance anxiety, anxiety and depression detector) were highly positively correlated; all were negatively correlated with the Core Self-Evaluation test, indicating that low self-efficacy is associated with higher psychological morbidity.

There were significant sex differences on all measures, with females consistently scoring higher than males. Younger musicians $(<30)$ were generally more vulnerable than older musicians, particularly on the K-MPAI and SPIN. These age effects were not gender specific. On a two-item screening test for depression, $32 \%$ warranted a fuller clinical evaluation. Those who answered "yes" to both questions had significantly higher scores on the anxiety measures (STAI-T, SPIN, and K-MPAI) compared with those who answered "yes" to one or neither question. For example, those who answered "yes" to both depression questions scored a mean of $120(S D=42)$ on the K-MPAI. Those who answered "yes" to one depression question scored on average $92(S D=29)$ on the K-MPAI while those who answered "no" to both questions had a mean of $75(S D=36)$ on the K-MPAI.

These results indicated convergent validity for the K-MPAI with clinical tests of anxiety and depression (Kenny et al., 2012). The K-MPAI was then assessed against tests validated in clinical populations in order to develop indicative preliminary cut-off scores for use with musician populations. Receiver Operating Characteristic (ROC) Curves were generated for established clinical screening tests (STAI-T, ADD, PRIME-MD, SPIN) using different scores to dichotomize these instruments with K-MPAI as the scale measure. The cut-point for K-MPAI using Youden's Index for STAI-T $\geq 65$ (1.5 SD above mean) was 105.3; using the cut point for STAI-T $\geq 60$ ( $1 \mathrm{SD}$ above mean), Youden's Index for K-MPAI was 104.5. For musicians answering yes to both depression questions on the PRIME-MD, the K-MPAI cutpoint was 118.5, for one of two questions, K-MPAI cut-point was 110. For $\mathrm{ADD}$, for those answering at least one question affirmatively, K-MPAI cut-point was 84.5 , for those answering at least three questions affirmatively, K-MPAI cut-point was 89.5. As previously identified, K-MPAI and SPIN were unrelated (Kenny, in press).

The K-MPAI has now been translated into several languages, including French, German, Spanish, Portuguese, Spanish (continente), Portuguese (continente) Italian, Cantonese, and

\begin{tabular}{|c|c|c|c|c|c|c|}
\hline Region & $\begin{array}{l}\text { Brass } \\
n=58\end{array}$ & $\begin{array}{c}\text { Woodwind } \\
n=67\end{array}$ & $\begin{array}{l}\text { Lower strings } \\
\qquad n=68\end{array}$ & $\begin{array}{l}\text { Upper strings } \\
\quad n=169\end{array}$ & $\begin{array}{c}\text { Percussion } \\
n=12\end{array}$ & $\begin{array}{c}\text { Total } \\
n=377\end{array}$ \\
\hline Shoulder and upper arm & $10.3(8.6)$ & $10.4(0)^{*}$ & $11.8(1.5)^{\#}$ & $10.1(8.9)$ & $16.7(8.3)$ & $11.1(6.1)^{\#}$ \\
\hline Elbow and forearm & $3.5(3.5)$ & $11.9(3)$ & $4.4(2.9)$ & $6.5(3.0)$ & $0(0)$ & $6.4(2.9)^{\wedge}$ \\
\hline Wrist and hand & $1.7(3.5)$ & $1.5(1.5)$ & $2.9(4.4)$ & $4.1(5.9)$ & $0(0)$ & $2.9(4.2)$ \\
\hline Thumb & $0(0)$ & $4.5(1.5)$ & $4.4(0)$ & $0(0)$ & $8.3(0)$ & $1.9(0.3)^{\wedge}$ \\
\hline Total & 13.8 & 29.9 & 25.0 & 21.3 & 25.0 & 22.3 \\
\hline
\end{tabular}

Comparison of left vs. right- ${ }^{\wedge} p<0.05$; ${ }^{\#} p<0.02 ;{ }^{*} p<0.01$. 
Polish $^{2}$, and studies are currently occurring in these and other countries to further ascertain its convergent and discriminant validity, clinical cut points, and sensitivity and specificity for use as a clinical instrument in the population of professional musicians. Early indications are encouraging that the K-MPAI is a robust clinical instrument that may be used for diagnosis and treatment planning (see, for example, Barbar et al., 2014; Kenny, in press).

In response to a question asking musicians to rank their selfidentified causes of MPA from a checklist containing 26 potential causes, the most commonly identified causes were "pressure from self," excessive physical arousal prior to or during a performance and inadequate preparation for the performance, health issues and "tendency to be anxious in general, not just in performance" (Table 3). Fifty-five percent musicians (55\%) identified that a generally high level of self-consciousness was a factor in their experience of performance anxiety. This checklist produced a very interesting pattern of results suggesting several directions for future research, including a deeper examination of the nature of the adverse experiences that exacerbated subsequent performance anxiety and how such experiences were encoded and processed by musicians.

Of interest, 78\% musicians identified a bad performance experience as one of the causes of ongoing music performance anxiety. The relationship between self-perceived worst performance experiences and their association with subsequent self-report of MPA has also been observed in adolescent musicians (Kenny and Osborne, 2006). Music students who reported a negative music performance experience scored significantly higher on measures of MPA than those who did not report such an experience. These same students also had higher scores on trait anxiety. A bad performance experience, which constitutes a specific psychological vulnerability in terms of Barlow's (2000) triple vulnerability theory, may potentiate performance anxiety in already vulnerable musicians. This result raises the possibility that elevated MPA may develop through exposure to premature evaluative performances in a competitive environment, which is some cases, may be traumatizing. As demonstrated by in-depth

${ }^{2}$ Certified translations of the K-MPAI in the languages specified above are available upon request from the author (dianna.kenny@sydney.edu.au).

Table 3 | Causes of music performance anxiety - most commonly self-identified and proportion ranked as most important.

\begin{tabular}{|c|c|c|}
\hline Potential cause & Chosen (\%) & Ranked $1(\%)$ \\
\hline Pressure from self & 89 & 29 \\
\hline $\begin{array}{l}\text { Excessive physical arousal prior to or } \\
\text { during a performance }\end{array}$ & 78 & 24 \\
\hline $\begin{array}{l}\text { Inadequate preparation for the } \\
\text { performance }\end{array}$ & 63 & 19 \\
\hline Health issues & 45 & 17 \\
\hline $\begin{array}{l}\text { Tendency to be anxious in general, not just } \\
\text { in performance }\end{array}$ & 37 & 15 \\
\hline
\end{tabular}

Percent $(n=377)$. interviews with professional orchestral musicians, such experiences may exert a lifelong effect, with many reporting such experiences in their formative years as a musician that have had profound effects on their subsequent management of their anxiety as adults (Kenny, 2011). Personal accounts reflected a degree of trauma resonant with post-traumatic stress. Indeed, 84 musicians (22\% of the sample) responded in the affirmative with respect to a question on post-traumatic stress disorder (PTSD) on the ADD. This was an unexpected finding suggesting the need for further investigation to understand the nature of these traumas and how they might impact on music performance.

With respect to the comparative effects of different performance settings on the experience of music performance anxiety, on a 10-point Likert scale, auditions were ranked the most anxiety-provoking (mean $=8.44 ; S D=2.07$ ), followed by solo performance, and oral presentation, which was ranked more anxiety-provoking than a chamber music performance or orchestral concert performance.

When asked to indicate which actions they took to alleviate their music performance anxiety, musicians most commonly identified they would increase their practice, practice deep breathing, increase their positive self-talk, seek mock performance opportunities, familiarize themselves with the performance venue and take beta blockers (Table 4). Further, $5 \%$ of musicians $(n=$ 17) reported drinking alcohol every day and $26.5 \%(n=89)$ drank on 5-6 days per week. Alcohol frequency (i.e., drinking every day) was significantly associated with higher scores on the K-MPAI, but not on STAI-T, SPIN, or ASI. Older musicians were more likely to be daily drinkers. These results suggest that some musicians may be using alcohol to manage their performance anxiety.

\section{Associations between physical and psychological factors}

Research with clinical populations has frequently observed a close relationship between reports of some forms of physical pain, in particular, chronic pain, fibromyalgia and those who frequently attend primary health care settings, with elevated psychological morbidity. This association has not been previously studied in professional musicians, despite the fact that this population experiences very high rates of performancerelated musculoskeletal pain/disorder (PRMD) (Bragge et al., 2006; Ackermann et al., 2011), with various reports placing

Table 4 | Actions taken to alleviate music performance anxiety-most commonly self-identified.

\begin{tabular}{lc}
\hline Action taken & Chosen (\%) \\
\hline Increase practice & 59 \\
Practice deep breathing & 50 \\
Increase positive talk & 46 \\
Seek mock performance opportunities & 45 \\
Familiarize themselves with the performance venue & 42 \\
Take beta blockers & 31
\end{tabular}

Percent $(n=377)$ 
the frequency between 60 and 90\% musicians. Our own study (Kenny and Ackermann, 2013) indicated that $84 \%$ professional orchestral musicians experienced PRMD, with 50\% at the time of the survey reporting that they were carrying an injury/pain condition.

Accordingly, we investigated the relationship between selfreported pain conditions, an objective pain measure [trigger point pain (TPP)] and psychological morbidity (depression and anxiety) in the same population of musicians. We assessed pain frequency and pain severity using 7-point Likert scales. Only 27\% musicians reported never having experienced pain related to a PRMD; 24\% reported being in constant pain and 21\% identified the intensity of their pain as "the worst imaginable." There was a highly significant positive association between pain frequency and pain intensity, and between pain severity and depression. Cluster analysis using K-MPAI with severity ratings of PRMD as inputs, identified four clusters, based on the severity of PRMD scores. A significant linear association between PRMD and K-MPAI was observed-higher PRMD scores were associated with higher K-MPAI scores.

However, a more complex picture emerged for depression and PRMD pain. For three of the four clusters, the association heldhigher PRMD severity-higher depression. The fourth cluster, however, comprising those who denied any depression (25\% musicians), reported the highest PRMD severity (Average score $=$ 6.65 out of a possible 7 ). By comparison, the group who answered "yes" to both depression questions scored an average 4.52 PRMD severity. We believe that this analysis may have identified a group of musicians who somatize their emotional distress - that is, they express their emotional pain in physical symptoms.

This is speculative and further research is needed to replicate this finding and to verify the conclusions drawn from it. Recent analyses suggest caution in over-attribution of the role of psychological factors. For example, Kenny (unpublished), using the Sound Practice database of 377 professional orchestral musicians, explored the relationship between the degree to which musicians reported recovering from performance-related physical injuries and psychological conditions such as depression, music performance anxiety and trait anxiety and found no relationship between speed or degree of recovery and these psychological factors.

Trigger point palpation (TPP in the upper trapezius muscles showed no association with PRMD severity or frequency, instead being sensitive to MPA severity. TPP ratings were highest for those reporting the highest levels of MPA and affirmative responses to both depression questions. There was a linear relationship between increasing TPP and MPA scores for the females. Men who reported the highest level of MPA, in contrast, recorded lower TPP scores than those with milder MPA. The reasons for this require further investigation.

\section{Interview study}

Below are examples of key themes that emerged. A more detailed account can be found in Kenny (2011).

(i) The struggle to separate one's musical identity from one's self-identity. One musician stated: "Music is my life, I don't do anything else." The inability to derive other sources of self-worth and self-esteem leaves musicians vulnerable to feeling like failures if they fail at musical tasks such as auditions or achieving perfect performances.

(ii) Internalized mental representations of parents which reveal the quality of attachment upon which the edifice of one's sense of self rests. Here is an example: My father was a frustrated musician... he's an intelligent man, fantastic set of ears, a good musician but he had no formal training. . . He can't see anything through. . he didn't give us that confidence to tackle things; we always worried that we would be failures, like him.

(iii) Generational transmission of music performance anxiety. This theme is related to (ii), with the addition that some musicians could make the nexus between their parents' anxiety and their own. My mum is a real worrier; she is wound up about everything. I am like that. . My mum does not seem to have come to terms with her anxiety and I have not come to terms with my anxiety... Sometimes I get nervous about the silliest things. She is like that, too. Others were keen not to pass on their own MPA to their children.

(iv) Adolescent onset of MPA. Many of the musicians reported sensitizing experiences during adolescence as the markers for the onset of severe MPA. I have always suffered from performance anxiety. The first time has always stayed with me. . it was related to feeling self-conscious getting up in front of hundreds of people... I thought, "WOW!" I did not know that my body could react in that way. . In that performance, I really fell apart. I got really nervous and my body just let me down. It was really embarrassing. It was my first awakening to performance anxiety.

(v) The stress of aging: One of our older players, a principal, was suffering very badly. We ... did a temporary job swap with another player to protect him and to alleviate his stress. When players get old, you can't control things the way you used to. He was unhappy about his playing and needed to alleviate his embarrassment.

(vi) "False alarms" (also called panic or panic attacks) appear uncued and unexpected and subsequently become conditioned in particular stressful situations that are associated with heightened threat or danger in people who have a specific psychological vulnerability and heightened neurobiological hyper reactivity. Note the description in adolescent onset of MPA, which is also an example of panic.

(vii) Cognitive effects of anxiety impair attention and memory, and capacity to sight read.

(viii) Situational factors: conductors, environmental challenges, work issues, lack of peer support (critical, competitive environment).

\section{Trial of ISTDP}

ISTDP's theoretical rationale draws on attachment theory (Bowlby, 1960, 1973), whose core therapeutic action is the "patient's actual experience of their true feelings about the present and the past" (Davanloo, 1990) (p. 2). Although psychodynamic in theoretical structure, the main areas of innovation of ISTDP lie in its therapeutic practices. Davanloo (1990, 2001, 2005) 
developed a technique to rapidly mobilize the unconscious therapeutic alliance, called the central dynamic sequence (Davanloo, 1987) in order to remove the major resistances to change, which are not effectively removed through interpretation alone. To date, one successful case study has been published (Kenny et al., 2014) and others are in preparation.

\section{HEARING}

\section{Usage hearing protection devices}

All orchestras in the study group were aware of the risks to their musicians and were actively taking some steps to reduce noise exposure, with varying degrees of effectiveness and understanding of the issues as reported by the authors previously (O'Brien et al., 2012). The reported regular use of adequate personal hearing protection by musicians was $64 \%$. Newly developed hearing protection devices incorporating active, level-dependent technology were found to be more acceptable to orchestral musicians who trialed these devices than any previous personal protective device, with results described in detail elsewhere (O'Brien et al., 2014).

\section{Exposure to noise}

During practice, sound levels were recorded at between 60 and $107 \mathrm{~dB} \mathrm{LA}_{\mathrm{eq}}$, with peak levels between 101 and $130 \mathrm{~dB} \mathrm{LC}_{\text {peak }}$. For average reported practice durations ( $2.1 \mathrm{~h}$ per day, 5 days a week), $53 \%$ would exceed accepted permissible daily noise exposure in solitary practice, in addition to sound exposure during orchestral rehearsals and performances. Similar to levels experienced in the orchestra, those most at risk of NIHL while practicing were the brass and percussion, with significant differences noted in sound levels recorded between ears in the violin, viola, flute/piccolo, horn, trombone, and tuba. Full details are described in the Journal of the Acoustical Society of America article (O'Brien et al., 2013a).

\section{SURVEILLANCE}

Following discussions with orchestra management and musicians, a paper-based system was implemented with the intention of musicians completing the two-page form on a regular basis before or after scheduled rehearsals, as it was expected this would maximize participation. Several important issues were identified during the trial implementation. These included allocating time for the form completion around the orchestra rehearsal schedule; balancing the frequency of data collection with the proportion of musicians who completed the forms; the level of detail of information collected; the areas covered by the data collection; the format of the form; and the musicians' perceptions of the usefulness of the information collected.

Subsequent to this first trial, a majority of musicians requested a web-based system. There was a range of opinions regarding the optimum frequency for data collection (weekly, fortnightly or four-weekly). Therefore, the first web-based system allowed the musician to choose the frequency of data entry. Uptake was better with the original web-based system but still low. The main issues identified were difficulties maintaining regular email contact (due to changing email addresses and firewall issues); developing a workable system of reminders; making the entry of data on anatomical site and symptoms simple; and maintaining interest amongst the musicians. The key area of improvements were determined to be the need for automatic regular feedback to musicians regarding the data they had entered previously and the ability to extract data easily for analysis purposes. A new surveillance system, developed in cooperation with the (Galbraith, 2014) which has an operating model for dance, is now being developed and will be trialed in 2014. This new version of the on-line system is menu-driven as much as possible, but it will be possible to enter text in some areas. Regular reminders are included and feedback is provided to allow the individual to compare their exposure data with others who play the same instrument and overall.

\section{DISCUSSION}

The Sound Practice program was designed to provide a detailed understanding of OHS aspects of being a professional orchestral musician in Australia, and to trial a series of interventions aimed to improve health and well-being in these musicians. To date, the study has provided a great deal of useful information on the complex health issues faced by professional orchestral musicians and on interventions that may be of benefit. A multidisciplinary approach has confirmed the interactive relationship between factors such as psychological and physical well-being, and reinforces the need for a holistic approach to better preventing and managing health issues arising in the orchestral workplace.

\section{PHYSICAL}

Orchestral musicians in Australia report a high rate of occupational injury, consistent with reports from overseas. There has been little change in these statistics over several decades (Fry, 1986; Fishbein et al., 1988). This may be related to little information being available on normal physical characteristics of performers, as well as a lack of evidence for effective intervention strategies. In addition, the loading induced by the instrument itself appeared to influence the site and nature of injury. Specific increased demands producing static postural loading (e.g., in the left shoulder of trombonists) and/or dynamic movement challenges (e.g., in the right shoulder of cellists) are thought to be the likely reason for this effect.

This study has provided normative values for musicians for many physical attributes (size, strength, and range of movement) of musicians and lends some support to the notion that musicians show some adaptive musculoskeletal changes in response to playing demands, such as the increased supination seen in the left forearm of violin and viola players (Ackermann and Driscoll, 2010; Ackermann et al., 2012).

The assessment protocol used a wide range of traditional physical tests that had been shown to be among the best available in terms of their sensitivity, specificity, and clinical utility in a usual clinical environment (Ackermann and Driscoll, 2010). However, these proved to be limited in assessing musicians' injuries. According to the measurements obtained, musicians, if anything, seem to show physical attributes above the normal benchmarks, as may be expected in an elite or "hyperfunctioning" population. As an example, the differences seen between the shoulder PRMDs in cellists and trombonists with distinctly different performance 
postural and biomechanical demands, and not identified in the standard clinical shoulder physical examination protocols, highlights the need for more specific clinical assessment approaches for musicians.

\section{PSYCHOLOGICAL}

In this study, the K-MPAI proved to be sensitive to age and sex differences and had significant correlations with most of the other anxiety measures, providing early evidence for the convergent validity of K-MPAI. The results highlight the need for broader psychological testing in the assessment of musicians presenting with problematic MPA, in particular, tests of PTSD and depression. Medication use should also be evaluated, given the high use in this population. Patient education of other psychological approaches should be included in management strategies.

As well as showing the extent of underlying psychological difficulties, this study also indicates that a complex relationship exists between psychological and physical wellbeing in this population. Professional orchestral musicians attending healthcare clinics for pain or injury conditions should be screened for psychological problems as attempts to treat the physical pain may not be effective unless the psychological issues are addressed simultaneously. Our findings provide some support for previous work (Leaver et al., 2011) indicating the need to be aware of possible somatization, and to continue with research to clarify the role of somatization in musicians whose injuries are not responsive to physical therapies. Screening tests will alert treating practitioners to the possible presence of psychological conditions that may need to be managed concurrently with the physical injury.

We strongly caution against over-attribution of psychological causes to physical injuries; each musician must be assessed individually to obtain a complete profile of their psychological and physical needs. The physical aspects of physical injuries must remain center stage in the treatment plan because a physical injury is often just that!

\section{HEARING}

The results show that musicians are at risk of NIHL while playing in the orchestra, but also face significant additional exposure during solitary practice, compounding their risk (O'Brien et al., 2012, 2013a). As has been previously recommended, the uptake and use of earplugs by musicians is unpopular (Laitinen and Poulsen, 2008; Zander et al., 2008) but needs to be increased to reduce the potential risk of NIHL (Emmerich et al., 2008; Jansen et al., 2009; Pawlaczyk-Łuszczyńska et al., 2010; Toppila et al., 2011). In Australia, while legislation has enhanced the use of earplugs and awareness of hearing issues, the findings in this study concur with the reports of hearing loss and dysfunction in orchestral musicians reported in these other international studies. Such data reinforces the need to continue to find better solutions to noise exposure as technology continues to develop in this field (O'Brien et al., 2013b, 2014). Focusing on educating musicians and orchestral management on best-practice hearing protection strategies is also important.

\section{SURVEILLANCE}

Useful surveillance is difficult to establish and maintain; must be developed taking particular account of the needs, interests, and attitudes of musicians; and is probably most likely to be effective with inclusion of regular and timely feedback to participants of their own results and the broader findings of the surveillance program.

\section{CONCLUSIONS}

The professional orchestral musician population remains susceptible to a range of workplace health and safety risks, but exposures vary between instruments and orchestras. Some specific areas that need to be addressed by further research include: refining models of musculoskeletal examination to include instrumentspecific evaluation; ensuring that the psychological well-being of a musician is evaluated in conjunction with any chronic or major playing-related health conditions; continuing to explore effective ways of protecting hearing without damaging the ultimate performance goal of making beautiful music; and further trial and modification of an on-line approach to musicians surveillance.

\section{ACKNOWLEDGMENTS}

This project was funded by the Australia Research Council (LP0989486), the Australia Council for the Arts, and the eight major state orchestras of Australia: Adelaide Symphony Orchestra, Australian Opera and Ballet Orchestra, Melbourne Symphony Orchestra, Orchestra Victoria, Queensland Symphony Orchestra, Sydney Symphony Orchestra, Tasmanian Symphony Orchestra, West Australian Symphony Orchestra. We thank James Strong for the Strong Review of Orchestras (2005) that motivated this study.

\section{REFERENCES}

Ackermann, B., and Adams, R. D. (2004). Perceptions of causes of performancerelated injuries by music health experts and injured violinists. Percept. Mot. Skills 99, 669-678. doi: 10.2466/PMS.99.6.669-678

Ackermann, B., and Driscoll, T. (2010). Development of a new instrument for measuring the musculoskeletal load and physical health of professional orchestra musicians. Med. Probl. Perform. Art. 25, 95-101.

Ackermann, B., Driscoll, T., and Kenny, D. T. (2012). Musculoskeletal pain and injury in professional orchestral musicians in Australia. Med. Probl. Perform. Art. 27, 183-189.

Ackermann, B., Kenny, D. T., and Fortune, J. (2011). Incidence of injury and attitudes to injury management in skilled flute players. Work 40, 255-259. doi: 10.3233/WOR-2011-1227

Axelsson, A., and Lindgren, F. (1981). Hearing in classical musicians. Acta Otolaryngol. Suppl. 377, 3-74.

Babor, T. F., Higgins-Biddle, J. C., Saunders, J. B., and Monteiro, M. G. (2001). The Alcohol Use Disorders Identification Test. Geneva: World Health Organization.

Barbar, A. E., Crippa, J. A., and Osorio, F. (2014). Parameters for screening music performance anxiety. Rev. Bras. Psiquiatr. 36, 245-247. doi: 10.1590/1516-44462013-1335

Barlow, D. (2000). Unravelling the mysteries of anxiety and its disorders from the perspective of emotion theory. Am. Psychol. 55, 1247-1263. doi: 10.1037/0003066X.55.11.1247

Borg, G. (1998). Borg's Perceived Exertion and Pain Scales. Champaign, IL: Human Kinetics.

Bowlby, J. (1960). Grief and mourning in infancy and early childhood. Psychoan. Study Child 15, 9-52.

Bowlby, J. (1973). Attachment and Loss: Separation, Anxiety and Anger. London: Hogarth. 
Bragge, P., Bialocerkowski, A., and McMeeken, J. (2006). A systematic review of prevalence and risk factors associated with playing-related musculoskeletal disorders in pianists. Occup. Med. 56, 28-38. doi: 10.1093/occmed/kqi177

Brandfonbrener, A. G. (2010). "Etiologies of medical problems in performing artists," in Performing Arts Medicine, eds R. T. Sataloff, A. G. Brandfonbrener, and R. J. Lederman (San Diego, CA: Singular Publishing Group), 25-50.

Connor, K. M. J., Davidson, R. T., Churchill, L. E., Sherwood, A., Foa, E., and Weisler, R. H. (2000). Psychometric properties of the Social Phobia Inventory (SPIN): new self-rating scale. Br. J. Psychiatry 176, 379-386. doi: 10.1192/bjp. 176.4.379

Davanloo, H. (1987). "The unconscious therapeutic alliance," in Frontiers of Dynamic Psychotherapy: Essays in Honor of Arlene and Lewis R. Wolberg, ed P. Buirski (Philadelphia, PA: Brunner/Mazel), 64-88.

Davanloo, H. (1990). Unlocking the Unconscious: Selected Papers of Habib Davanloo. Oxford: Wiley and Sons.

Davanloo, H. (1995). Intensive short-term dynamic psychotherapy: spectrum of psychoneurotic disorders. Int. J. Short Term Psychother. 10, 121-155.

Davanloo, H. (2001). Intensive short-term dynamic psychotherapy: extended major direct access to the unconscious. Eur. Psychother. 12, 25-70.

Davanloo, H. (2005). "Intensive short-term dynamic psychotherapy," in Kaplan and Sadock's Comprehensive Textbook of Psychiatry, eds B. Sadock and V. Sadock (New York, NY: LippincottWilliamsWilkins).

Driscoll, T., and Ackermann, B. (2012). Applied musculoskeletal assessment: results from a standardised physical assessment in a national population of professional orchestral musicians. Rheumatology S2:005. doi: 10.4172/2161-1149.S2-005

Emmerich, E., Rudel, L., and Richter, F. (2008). Is the audiologic status of professional musicians a reflection of the noise exposure in classical orchestral music? Eur. Arch. Otorhinolaryngol. 82, 153-164. doi: 10.1007/s00405-007-0538-z

Fishbein, M., Middlestadt, S. E., Ottati, V., Straus, S., and Ellis, A. (1988). Medical problems among ICSOM musicians: overview of a national survey. Med. Probl. Perform. Art. 3, 1-8.

Fry, H. J. H. (1986). Incidence of overuse syndrome in the symphony orchestra. Med. Probl. Perform. Art. 1, 51-55.

Galbraith, G. (2014). Dancer Wellness Project. Avilable online at: www. dancerwellnessproject.com/

Hasson, D., Theorell, T., Liljeholm-Johansonn, Y., and Canlon, B. (2009). Psychosocial and physiological correlates of self-reported hearing problems in male and female musicians in symphony orchestras. Int. J. Psychophysiol. 74, 93-100. doi: 10.1016/j.ijpsycho.2009.07.009

James, I. (1997). Federation Internationale des Musiciens 1997 Survey of 56 Orchestras Worldwide. London: British Association for Performing Arts Medicine.

James, I. (1998). Western orchestral musicians are highly stressed [France]. Resonance 26, 19-20.

Jansen, E., Helleman, H., Dreschler, W., and de Laat, J. (2009). Noise induced hearing loss and other hearing compaints among musicians of symphony orchestras. Int. Arch. Occup. Environ. Health 82, 153-164. doi: 10.1007/s00420-0080317-1

Jansson, E., and Karlsson, K. (1983). Sound levels recorded within the symphony orchestra and risk criteria for hearing loss. Scand. Audiol. 12, 215-221. doi: 10.3109/01050398309076249

Judge, T. A., Erez, A., Bono, J. E., and Thoresen, C. J. (2003). The core selfevaluations scale: development of a meaure. Pers. Psychol. 56, 303-331. doi: 10 1111/j.1744-6570.2003.tb00152.x

Kähäri, K., Axelsson, A., Hellström, P., and Zachau, G. (2001). Hearing assessment of classical orchestral musicians. Scand. Audiol. 30, 13-23. doi: 10.1080/01050 3901750069536

Kenny, D. T. (in press). "Identifying cut-off scores for clinical purposes for the Kenny Music Performance Anxiety Inventory (K-MPAI) in a population of professional orchestral musicians in Australia," in Polish Psychological Bulletin (Invited paper for the Special Edition on Music Performance Anxiety).

Kenny, D. T. (2009). "Negative emotions in music making: performance anxiety," in Handbook of Music and Emotion: Theory, Research, Applications, eds P. Juslin and J. Sloboda (Oxford: Oxford University Press), 425-451.

Kenny, D. T. (2011). The Psychology of Music Performance Anxiety. Oxford: Oxford University Press. doi: 10.1093/acprof:oso/9780199586141.001.0001

Kenny, D. T., and Ackermann, B. (2013). Performance-related musculoskeletal pain, depression and music performance anxiety in professional orchestral musicians: a population study. Psychol. Music. doi: 10.1177/0305735613493953. Available online at: http://pom.sagepub.com/content/early/2013/09/02/ 0305735613493953.

Kenny, D. T., Arthey, S., and Abbass, A. (2014). Intensive short-term dynamic psychotherapy for severe music performance anxiety: assessment, process, and outcome of psychotherapy with professional orchestral musician. Med. Probl. Perform. Art. 29, 3-7.

Kenny, D. T., Driscoll, T., and Ackermann, B. (2012). Psychological well-being in professional orchestral musicians in Australia: a descriptive population study. Psychol. Music 42, 210-232. doi: 10.1177/0305735612463950

Kenny, D. T., and Osborne, M. S. (2006). Music performance anxiety: new insights from young musicians. Adv. Cogn. Psychol. 2, 103-112. doi: 10.2478/v10053008-0049-5

Laitinen, H., and Poulsen, T. (2008). Questionnaire investigation of musicians' use of hearing protectors, self reported hearing disorders, and their experience of their working environment. Int. J. Audiol. 47, 160-168. doi: $10.1080 / 14992020801886770$

Leaver, R., Harris, E. C., and Palmer, K. T. (2011). Musculoskeletal pain in elite professional musicians from British symphony orchestras. Occup. Med. 61, 549-555. doi: 10.1093/occmed/kqr129

Lee, J., Behar, A., Kunov, H., and Wong, W. (2005). Musicians noise exposure in the orchestra pit. Appl. Acoust. 66, 919-931. doi: 10.1016/j.apacoust.2004.11.009

Manchester, R. A. (2007). Epistemology and the performing arts. Med. Probl. Perform. Art. 22, 41.

Means-Christensen, A. J., Sherbourne, C. D., Roy-Byrne, P. P., Craske, M. G., and Stein, M. B. (2006). Using five questions to screen for five common mental disorders in primary care: diagnostic accuracy of the Anxiety and Depression Detector. Gen. Hosp. Psychiatry 28, 108-118. doi: 10.1016/j.genhosppsych.2005. 08.010

Meinke, W. B. (1998). Risks and realities of musical performance. Med. Probl. Perform. Art. 13, 56.

Obeling, L., and Poulsen, T. (1999). Hearing ability in Danish symphony orchestra musicians. Noise Health 1, 43-49.

O’Brien, I., Ackermann, B., and Driscoll, T. (2013a). Sound exposure of professional orchestral musicians during solitary practice. J. Acoust. Soc. Am. 4, 1-7. doi: 10.1121/1.4820900

O'Brien, I., Wood, J., and Ackermann, B. (2013b). Assessment of an acoustic screen used for sound exposure management in a professional orchestra. Acoust. Aust. 41, 149-153.

O'Brien, I., Driscoll, T., and Ackermann, B. (2012). Hearing conservation and noise management practices in professional orchestras. J. Occup. Environ. Hyg. 9, 602-608. doi: 10.1080/15459624.2012.715519

O'Brien, I., Driscoll, T., Williams, W., and Ackermann, B. (2014). A clinical trial of active hearing protection for orchestral musicians. J. Occup. Environ. Hyg. 11, 450-459. doi: 10.1080/15459624.2013.875187

O'Brien, I., Wilson, W., and Bradley, A. (2008). Nature of orchestral noise. J. Acoust. Soc. Am. 124. doi: 10.1121/1.2940589

Paarup, H. M., Baelum, J., Holm, J. W., Manniche, C., and Wedderkopp, N. (2011). Prevalence and consequences of musculoskeletal symptoms in symphony orchestra musicians vary by gender: a cross-sectional study. BMC Musculoskelet. Disord. 12:223. doi: 10.1186/1471-2474-12-223

Pawlaczyk-Łuszczyńska, M., Dudarewicz, A., Zamojska, M., and ŚliwińskaKowalska, M. (2010). Hearin ability in orchestral musicians. Arch. Acoust. 35, 579-594. doi: 10.2478/v10168-010-0044-y

Ranelli, S., Straker, L., and Smith, A. (2011). Playing-related musculoskeletal problems in children learning instrumental music. Med. Probl. Perform. Art. 26, 123-139.

Schmidt, J., Pedersen, E., Juhl, P., Christensen-Dalsgaard, J., Andersen, T., Poulsen, T., et al. (2011). Sound exposure of symphony orchestra musicians. Ann. Occupat. Hyg. 55, 893-905. doi: 10.1093/annhyg/mer055

Spielberger, C. D., Jacobs, G., Russell, S., and Crane, R. S. (1983). Assessment of anger: the state-trait anger scale. Adv. Pers. Asses. 2, 159-187.

Spitzer, R. L., Kroenke, K., and Williams, B. W. J. (1999). Validation and utility of a self-report version of PRIME-MD. JAMA 282, 1737-1744. doi: 10.1001/jama.282.18.1737

Strong, J. (2005). A New Era. Report of the Orchestras Review 2005. Canberra, ACT: Australian Government; Department of Communications, Information Technologies and the Arts. 
Toppila, E., Koskinen, H., and Pyykkö, I. (2011). Hearing loss among classical orchestra musicians. Noise Health 13, 45. doi: 10.4103/1463-1741. 74001

Wilson, W., O'Brien, I., and Bradley, A. (2013). The audiological health of horn players. J. Occupat. Environ. Hyg. 11, 590-596. doi: 10.1080/15459624.2013. 818227

Zander, M., Spahn, C., and Richter, B. (2008). Employment and acceptance of hearing protectors in classical symphony and opera orchestras. Noise Health 10, 14. doi: 10.4103/1463-1741.39004

Conflict of Interest Statement: The authors declare that the research was conducted in the absence of any commercial or financial relationships that could be construed as a potential conflict of interest.
Received: 28 February 2014; accepted: 16 August 2014; published online: 09 September 2014.

Citation: Ackermann BJ, Kenny DT, O'Brien I and Driscoll TR (2014) Sound Practice-improving occupational health and safety for professional orchestral musicians in Australia. Front. Psychol. 5:973. doi: 10.3389/fpsyg.2014.00973

This article was submitted to Cognitive Science, a section of the journal Frontiers in Psychology.

Copyright (C) 2014 Ackermann, Kenny, O'Brien and Driscoll. This is an open-access article distributed under the terms of the Creative Commons Attribution License (CC BY). The use, distribution or reproduction in other forums is permitted, provided the original author(s) or licensor are credited and that the original publication in this journal is cited, in accordance with accepted academic practice. No use, distribution or reproduction is permitted which does not comply with these terms. 